\title{
Level of Awareness about HIV/AIDS among Ever Married Women in Bangladesh
}

\author{
Md Nazrul Islam Mondal*, Md Mahfuzar Rahman, Md Obaidur Rahman, Mst Naznin Akter
}

Department of Population Science, and Human Resource Development, University of Rajshahi, Rajshahi, 6205, Bangladesh

\begin{abstract}
Ever married women are more vulnerable group to sexually transmitted diseases (STDs), HIV/AIDS infection, and unplanned pregnancies. The aims of this study are to assess the level of awareness among ever married women on HIV/AIDS and to determine the affecting factors influenced knowledge and awareness about HIV/AIDS regarding its prevention and control. The data on 10,996 ever married women in their reproductive span (15-49 years) was taken from the Bangladesh Demographic and Health Survey (BDHS), 2007. The statistical tools, Chi square $\left(\chi^{2}\right)$ test and binary logistic regression analysis have been performed to analyse the data. Both bivariate and multivariate analyses identified that respondent's education, husband's education, husband's occupation, age at marriage, watching TV, electricity in the household, marital status, and residence are found to have statistically significant effects with HIV/AIDS awareness $(\mathrm{p}<0.01)$. Marriage in the older age ( $>18$ years), education, and mass media campaigns are strongly suggested for increasing knowledge and awareness to be controlled the spread of HIV/AIDS as well as STDs among ever married women in Bangladesh.
\end{abstract}

Keywords Ever married women, STDs, HIV, AIDS, reproductive span, logistic regression

\section{Introduction}

Acquired immunodeficiency syndrome (AIDS) pandemic is an infectious disease caused by human immunodeficiency virus (HIV) that has created a global catastrophe. Once HIV starts damaging the human immune system, it ultimately develops AIDS and ends in death[1]. It is a condition when the immune system begins to fail and leads to life- threatening opportunistic infections. The existence of HIV/AIDS poses a serious challenge to human being and its impact on a country is tremendous. HIV is a retrovirus that can lead to AIDS and considered as a severe global health problem. The pandemic has affected most countries in the world. In 2010, the total number of people living with HIV was 34.0 million in which with adult prevalence rate $0.8 \%$, in which women prevalence rate $0.6 \%$, newly infected with HIV was 2.7 million, the number of deaths due to AIDS was 1.8 million[2]. In Eastern Europe and Central Asia, the number of people living with HIV rose $250 \%$ from 2001 to 2010[2]. Every day, over 6800 persons become infected with HIV and over 5700 persons die from AIDS, mostly because of inadequate access to HIV prevention and treatment services[3]. In many developing countries, HIV prevalence was above $1 \%$, but in none of the developed countries, HIV prevalence has ever crossed the $1 \%$ mark[4].

* Corresponding author:

E-mail: nazrul_ru@yahoo.com (Nazrul Islam Mondal)

Published online at http://journal.sapub.org/fph

Copyright (C) 2012 Scientific \& Academic Publishing. All Rights Reserved
In October 1989 the first HIV positive case was detected in Bangladesh[5]. The person was a foreigner. He was later deported to his country. The first Bangladesh HIV positive and AIDS patients were detected in May 1990. The HIV positive case a migrant worker and the AIDS patient was a seaman. After detecting AIDS the seaman was deported and sent back to Bangladesh. He was treated under the close observation of National AIDS Committee (NAC) of Bangladesh and later died in March 1991.The overall prevalence of HIV in Bangladesh is relatively low but infection has reached significant proportions in certain high-risk groups and may soon spread to other groups[6]. Most of the people who are engaged in high risk behaviors do not know how HIV is transmitted and are not aware that their behavior puts them at risk[7]. The ability of the peoples' either knowledge about HIV/AIDS or the mode of its transmission as well as its prevention is very limited[8]. In Bangladesh, the HIV prevalence in the general population appears low $(<0.2 \%)$, and is estimated as $<1 \%$ in all risk groups except for injecting drug users (IUD) (7\%) [9]. Although the exact number of HIV cases is not known, by 2010, total 2088 cases of HIV had been confirmed in which 250 cases of HIV had been newly diagnosed and of these people, 850 had developed AIDS in which 143 was newly diagnosed and 241 had died where 39 new death occurred, a much higher number than in previous years[9]. Dhaka and Sylhet are the most vulnerable places of HIV because there are $54(21.6 \%)$ and $53(21.2 \%)$ HIV infected people of the total newly diagnosed HIV people in 2010 respectively[9]. Again, among the total newly diagnosed HIV people in $2009,82.4 \%$ belonged to $16-45$ 
years of age, $67.6 \%$ was male and $30.4 \%$ was female and most of them (77.2\%) were married[9]. So, it is clear that married women are the most vulnerable group and they are at greater risk in acquisition and transmission HIV and AIDS epidemics.

Bangladesh is considered a high-risk country for several reasons. Bangladesh is geographically vulnerable to HIV/AIDS due to its high prevalence (various degrees of the epidemic) to India, Myanmar, Nepal and Thailand. Bangladesh is bordered by India on the East, West and North and a border strip with Myanmar on the South. India alone has 2.5 million people living with HIV/AIDS with a prevalence rate of $0.36 \%$ which is more than half of all the people living with HIV/AIDS in Asia[3]. Furthermore, Bangladesh has a close trade ties with Thailand. The epidemic is severe in all these countries. But knowledge about this virus and its transmission still remains incomplete[10]. Among the adolescents, girls are more vulnerable to sexually transmitted diseases (STDs) including HIV/AIDS, especially through heterosexual intercourse with others than their male counterparts. All these potential factors fuel to the rise in HIV acquisition and transmission. If this situation continues, Bangladesh will face a crisis, as a developing country, it does not have the resources to tackle. It will be unable to mitigate the harmful impact of widespread HIV/AIDS, especially be unable to afford the medication costs. Since a cure or vaccine is unlikely in the near future, efforts to prevent the HIV epidemic must focus on public awareness. Several countries, including Thailand and Uganda, have successfully decreased the spread of HIV by aggressive efforts in this regard. Consequently, there is an urgent need for a comprehensive prevention program to control the spread of HIV/AIDS in Bangladesh[11]. In this critical situation, public awareness can play a dominating role in preventing HIV/AIDS epidemic[12]. Useful and fruitful media campaigns are strongly suggested for creating knowledge and awareness to be controlled the spread of HIV and AIDS[13]. Mass awareness campaigns on HIV/AIDS could improve the critical situation[14]. The STDs are increasing the likelihood of HIV transmission as well as having other reproductive health consequences of ever married women. Obviously, it is important to explore and identify the relations of those factors for which AIDS awareness modifies significantly in the context of Bangladesh among the ever married women. Therefore, the present study has aimed to examine the association between AIDS awareness and a set of independent variables of ever married women in Bangladesh.

\section{Data and Methods}

The data for this study were obtained from the Bangladesh Demographic and Health Survey (BDHS), 2007[15]. It provides up-to-date information on the population and health situation in Bangladesh. The 2007 BDHS is the fifth national demographic and health survey conducted in the country. The survey is based on a nationally representative sample. It is the cross-sectional survey that has been carried out since 1993 among a nationally representative sample of women as done in many other countries. It provides estimates for rural and urban areas of the country, and for each of the six divisions. The BDHS is the part of the global Demographic and Health Surveys (DHS) program, which collects information on a number of areas such as demographic characteristics, reproductive history, family planning, and knowledge and attitudes regarding HIV/AIDS and other sexually transmitted infections (STIs). The BDHS was conducted through a collaborative effort of the National Institute of Population Research and Training (NIPORT) in Bangladesh; Macro International, USA; and Mitra \& Associates during the period from 24 March to 11 August 2007. A nationally representative multistage cluster sample design was used for the sample survey in which a total of 10,400 households (response rate $99 \%), 10,996$ currently married women (15-49 years) (response rate $98 \%$ ) and 3,771 currently married men (age 15-54) (response rate 93\%) were successfully interviewed. The set of independent variables are women educational attainment, husband's education, husband's occupation, age at marriage, has electricity in the household, marital status, area of residence, which determine the socio-economic status of the respondents, along with some programmatic variables such as watching TV at least once a week, involvement any one of the organizations (such as Grameen Bank, BRAC, ASA, PROSHIKA, BRDB, Mother's Club, and other organizations). The dependent variable, 'ever heard HIV/AIDS' used to determine the status of HIV/AIDS awareness, was coded as 1 for yes as 0 for not at all. Both bivariate (chi-square test) and multivariate techniques (logistic regression model) have been performed to assess the factors associated with HIV/AIDS awareness of the ever married women in Bangladesh. The coded data has been entered in the computer and the data has been analysed using the computer software SPSS 17.0.

\section{Results and Discussion}

\subsection{Background Characteristics of the Respondents}

Table 1 shows the distribution of females who ever heard HIV/AIDS by various independent variables. The corresponding results of logistic regression analysis are presented in Table 2.

HIV/AIDS is as the bubonic plague of time for Bangladesh to take strong initiatives to provide HIV/AIDS and sex related education in the school context. Because many people are still traditional, thinking sexuality is a private matter, they hesitate to talk about it and young people have not sufficient knowledge about HIV/AIDS. Though HIV/AIDS is a talking point on street corners, many people still are not informed scrupulously what HIV/AIDS absolutely means and they are not informed how to keep safe themselves as well. In this regard gender literacy may play an important role to make aware of HIV/AIDS. By this time, in Bangla- 
desh, HIV/AIDS increased acute threats to the education system over the years. It has affected the education programs and projects comprehensively. The principle of present national curriculum has highlighted the learning need issues linked to the HIV/AIDS epidemic prevention, such as general health awareness, safe sex practices, coping with illness and death in the family, lessening discrimination towards people living with HIV/AIDS and enhancing life skills. Consequently it has an integrated impact on ministries, departments, agencies, and policy makers liable for proper scheduling and allocation of education resources and services. The Ministry of Education of Bangladesh has a great liking to take a number of initiatives to prevent HIV/AIDS from spreading with the help of NGOs to ensure community people's participation. In this regard some NGOs are already conducting various programs to achieve 'goal number 6 ' of Millennium Development Goals (MDGs) which includes one target related to HIV/AIDS, namely to have halted the epidemic by 2015 and begun to reverse its spread.

Table 1. Distribution of the respondents who ever heard HIV/AIDS by several characteristics of the respondents

\begin{tabular}{|c|c|c|c|}
\hline Characteristics & $\begin{array}{l}\text { Number of } \\
\text { females }\end{array}$ & $\begin{array}{l}\text { Heard about } \\
\text { HIV/AIDS }\end{array}$ & $\begin{array}{c}\text { Do not heard } \\
\text { about HIV/AIDS }\end{array}$ \\
\hline \multicolumn{4}{|c|}{ Respondent education* } \\
\hline Illiterate & $33528(32.08)$ & $1579(44.76)$ & $1949(55.24)$ \\
\hline Literate & $7468(67.92)$ & $6108(81.79)$ & $1360(18.21)$ \\
\hline \multicolumn{4}{|c|}{ Husband education* } \\
\hline Illiterate & $3617(32.89)$ & $1819(50.29)$ & 1798(49.71) \\
\hline Literate & $7379(67.11)$ & $5868(79.52)$ & $1511(20.48)$ \\
\hline \multicolumn{4}{|c|}{ Husband occupation* } \\
\hline Manual & 9296(84.54) & $6201(66.71)$ & $3095(33.29)$ \\
\hline Didn't work & $415(3.77)$ & $297(71.57)$ & $118(28.43)$ \\
\hline Non-manual & $1285(11.69)$ & $1189(92.53)$ & $96(7.47)$ \\
\hline \multicolumn{4}{|c|}{ Age at marriage* } \\
\hline$<18$ years & $8842(80.41)$ & $5888(66.59)$ & $2954(33.41)$ \\
\hline$\geq 18$ years & $2154(19.59)$ & $1799(83.52)$ & $355(16.48)$ \\
\hline \multicolumn{4}{|c|}{ Watching TV* } \\
\hline No & 4883(44.41) & $2339(47.90)$ & $2544(52.10)$ \\
\hline Yes & $6113(55.59)$ & $5348(87.49)$ & $765(12.51)$ \\
\hline \multicolumn{4}{|c|}{ Electricity in the household* } \\
\hline No & $5696(51.80)$ & $3193(56.06)$ & $2503(43.94)$ \\
\hline Yes & $5300(48.20)$ & 4494(84.79) & $806(15.21)$ \\
\hline \multicolumn{4}{|c|}{ Involvement any organizations } \\
\hline No & $7009(63.74)$ & 4920(70.20) & $2089(29.80)$ \\
\hline Yes & $3987(36.26)$ & $2757(69.15)$ & $1230(30.85)$ \\
\hline \multicolumn{4}{|l|}{ Marital status* } \\
\hline $\begin{array}{c}\text { Currently } \\
\text { married }\end{array}$ & $10146(92.27)$ & 7203(70.99) & 2943(29.01) \\
\hline Others & $850(7.73)$ & 484(56.94) & $366(43.06)$ \\
\hline \multicolumn{4}{|c|}{ Area of residence* } \\
\hline Rural & $6845(62.25)$ & $4138(60.45)$ & $2707(39.55)$ \\
\hline Urban & 4151(37.75) & $3549(85.50)$ & $602(17.50)$ \\
\hline
\end{tabular}

Note: * indicates that these variables are significantly $(\mathrm{p}<0.01)$ associated with the level of awareness about HIV/AIDS for the respondents; the numbers indicated in the parentheses are the percentages.

The results indicate that the educational status (literate $67.92 \%$ and illiterate $32.08 \%$ ) increases the respondents' awareness about HIV and AIDS epidemics. Almost all $(81.80 \%)$ of the literate women and around half $(44.76 \%)$ of the illiterate ever married women have heard about HIV and AIDS. A few number (18.21\%) of literate women and more than half $(55.24 \%)$ of the illiterate women do not heard about HIV/AIDS. This result is similar to the result of the study of Shahidullah et al. [16] because they found that almost $(97.00 \%)$ of the respondents had heard the name of HIV/AIDS. Though it is not sufficiently enough, it is expected most that people at least seems to know about AIDS. Often knowledge and awareness of the women relies on their husbands' education and occupation. The findings of this study demonstrated that the one-third $(32.89 \%)$ husbands are illiterate of them $50.29 \%$ have heard about HIV/AIDS and most of the husbands $(67.11 \%)$ are literate of them almost all (79.52\%) have heard about HIV and AIDS. It is a positive sign because Sultana[14] found that education plays an important role in preventing HIV/AIDS. Husband's occupation is an important predictor which helps his wife understanding through discussion about various topics especially STDs. There are $84.54 \%$ and $11.69 \%$ respondents whose husbands are involved with manual and non-manual (doctor, lawyer, teacher, banker, large businessman etc.) works and of which, $66.71 \%$ and $92.53 \%$ ever heard about HIV/AIDS respectively. Clearly, husbands of the respondents employed in the manual works bear least knowledge about HIV and AIDS than the wives of the husbands employed as non-manual works. According to the constitutional law of Bangladesh, the legal age at marriage for female is 18 years. The results indicate that the number of respondents with age at marriage under 18 years old is $80.41 \%$ of them $66.59 \%$ ever heard HIV/AIDS. Early marriage is harmful for the females because it is the cause of early pregnancy and producing more children which affects fertility, reproductive health and their lives. On the other hand, the respondents with age at marriage 18 years and above is $19.59 \%$ and of which, $83.52 \%$ ever heard HIV/AIDS. It is an important finding of this study that there is a positive relationship between age at marriage and awareness about HIV and AIDS epidemics. Mass media can play a strong role in creating awareness about HIV/AIDS. It is usual to have awareness among the people who retain themselves in close contact to mass media and electronic media like radio, TV. Less than half $(44.41 \%)$ of the respondents do not watch TV and more than half $(55.59 \%)$ of the respondents watch TV at least once a week. Women who watch TV at least once a week possess the highest percentage $(87.49 \%)$ of awareness but around half $(47.90 \%)$ of the respondents who do not watch TV are not aware. This result is similar to the result of the study by Rahman and Rahman[18] because they found that media particularly TV and education play the leading role regarding this issue and $77.10 \%$ married women who watch TV regularly have better knowledge on HIV/AIDS than who do not watch TV regularly. Electricity in the household symbolizes the economic status of the respondents. In this study, it is identified that around half of the respondents $(48.80 \%)$ have electricity in the household of them $84.79 \%$ of the respondents are aware about HIV/AIDS. On the other hand, half $(51.80 \%)$ of the respondents house are not electrified, of them $43.94 \%$ women do not know 
about this epidemic. In Bangladesh, nongovernmental organizations (NGOs) are playing a vital role in developmental efforts in the diversified sectors. Among the ever-married women only one-third (36.20\%) are involved with any of the organization (such as Grameen Bank, BRAC, ASA, PROSHIKA, BRDB, Mother's Club, and other organizations) and there has no significance difference in case of HIV awareness, i.e., the NGOs' roles regarding HIV awareness are not remarkable. Marital status is an important predictor of the HIV awareness. In this study marital status has been classified into two categories as currently married $(92.27 \%)$ and others $(7.73 \%)$ which included separated, divorced, widowed, and never married. The currently married women are more aware (70.99\%) about HIV and AIDS than that of others $(56.94 \%)$. Bangladesh is a country of rural dominated and often lack of various facilities available in urban areas. The results showed that around two-third (62.25\%) respondents live in the rural areas; among them $60.45 \%$ are aware about HIV and AIDS epidemics. On the other hand, around one-third $(37.75 \%)$ respondents live in the urban areas of which $85.50 \%$ are aware about HIV and AIDS epidemics. Thus, the women in the urban areas are more aware about HIV and AIDS.

Table 2. Results of logistic regression analysis of HIV/AIDS awareness for the respondents

\begin{tabular}{|c|c|c|c|c|c|}
\hline \multirow[t]{2}{*}{ Variables } & \multirow{2}{*}{$\begin{array}{l}\text { Coefficients } \\
\qquad(\beta)\end{array}$} & \multirow[t]{2}{*}{ P-value } & \multirow{2}{*}{$\begin{array}{l}\text { Odds } \\
\text { ratio } \\
\text { (OR) } \\
\end{array}$} & \multicolumn{2}{|c|}{$\begin{array}{c}95 \% \text { CI for the } \\
\text { OR }\end{array}$} \\
\hline & & & & Lower & Upper \\
\hline \multicolumn{6}{|c|}{ Respondent education } \\
\hline Illiterate(R) & & & 1.000 & & \\
\hline Literate & 1.207 & 0.000 & 3.344 & 3.006 & 3.720 \\
\hline \multicolumn{6}{|c|}{ Husband education } \\
\hline Illiterate (R) & & & 1.000 & & \\
\hline Literate & 0.506 & 0.000 & 1.658 & 1.491 & 1.845 \\
\hline \multicolumn{6}{|c|}{ Husband occupation } \\
\hline Manual (R) & & & 1.000 & & \\
\hline Didn't work & 0.079 & 0.547 & 1.082 & 0.836 & 1.401 \\
\hline Non-manual & 0.742 & 0.000 & 2.099 & 1.656 & 2.661 \\
\hline \multicolumn{6}{|c|}{ Age at marriage } \\
\hline$<18$ years $(\mathrm{R})$ & & & 1.000 & & \\
\hline$\geq 18$ years & 0.394 & 0.000 & 1.483 & 1.283 & 1.715 \\
\hline \multicolumn{6}{|l|}{ Watching TV } \\
\hline No (R) & & & 1.000 & & \\
\hline Yes & 1.410 & 0.000 & 4.094 & 3.676 & 4.559 \\
\hline \multicolumn{6}{|c|}{ Electricity in the household } \\
\hline No (R) & & & 1.000 & & \\
\hline Yes & 0.510 & 0.000 & 1.665 & 1.486 & 1.866 \\
\hline \multicolumn{6}{|c|}{ Marital status } \\
\hline $\begin{array}{l}\text { Currently } \\
\text { married }(\mathrm{R})\end{array}$ & & & 1.000 & & \\
\hline Others & -0.340 & 0.000 & 0.712 & 0.598 & 0.847 \\
\hline \multicolumn{6}{|c|}{ Area of residence } \\
\hline Rural (R) & & & 1.000 & & \\
\hline Urban & 0.702 & 0.000 & 2.017 & 1.789 & 2.274 \\
\hline
\end{tabular}

Note: R represents the reference category, and CI represents the confidence of the odds ratio

Chi-square test $(\chi 2)$ has been used to determine the association between dependent and independent variables as bivariate techniques. Table 1 also reveals that respondent's education, husband education, husband occupation, age at marriage, watching TV, has electricity in the household, marital status and area of the respondents are significantly associated $(p<0.01)$ the with level of awareness of HIV/AIDS of studied population. This result is similar to the result of of Rahman and Rahman[17] because they also found that education, husband education, husband occupation, media particularly watching TV and area of residence were significantly associated with level of awareness of HIV/AIDS of married women. On the other hand, only the respondent's involvement in any organization is not statistically significantly associated with level of awareness of HIV/AIDS of ever married women.

Binary logistic regression analysis has been carried out as multivariate techniques to assess the net effects of independent variables on HIV/AIDS awareness of the ever married women in Bangladesh. In this analysis, all the independent variables are coded in dummy coding scheme. Odds ratio (OR) has been used to compare different groups with 95\% confidence interval (CI) presented in Table 2.

The results of the binary logistic regression analysis revealed that education, age at marriage, watching TV, has electricity in the household, involvement in any organization, marital status and area of residence as having statistically significant relationships $(\mathrm{p}<0.01)$ with HIV and AIDS awareness of the respondents. Education is an event of human life that carried out a significant role in determining his/her social status. From Table 2, it is showed that the regression coefficient for the literate ever-married women is 1.207 and the corresponding $\mathrm{OR}$ is 3.344 ( $\mathrm{CI}=3.006-3.720)$, which implies that the level of awareness about HIV/AIDS among the literate ever-married women are 3.34 times higher than that of the illiterate ever-married women. So, education plays a vital role in creating awareness about HIV and AIDS among the ever married women. The regression coefficient for the literate husbands of ever-married women is 0.506 and the corresponding $\mathrm{OR}$ is $1.658(\mathrm{CI}=1.491-1.845)$, which implies that the level of awareness about HIV/AIDS among the literate husband of ever-married women are 1.658 times higher than that of the illiterate husband of ever-married women. It is clear that wives of the educated husbands know better about HIV/AIDS than the wives of the uneducated husbands. Again, the regression coefficients for the non-manual occupied husbands and not working husband of ever-married women is 0.742 and 0.079 and the corresponding $\mathrm{OR}$ are 2.099 ( $\mathrm{CI}=1.656-2.661)$ and 1.082 $(\mathrm{CI}=0.836-1.401)$ respectively, which implies that the level of awareness about HIV/AIDS among the non-manual occupied husbands and not working husbands of ever-married women are 2.099 times and 1.082 times higher than that of the manual occupied husbands of ever-married women. So, it is clear that occupation determines largely the social status of an individual and awareness level varies with their professions. The regression coefficients for the ever-married women whose age at marriage is 18 years and above is 0.394 and the corresponding OR is $1.483(\mathrm{CI}=1.283-1.715)$, which implies that the level of awareness about HIV/AIDS among the ever-married women whose age at marriage is 18 years and above is 1.483 times higher than that of the ever-married 
women whose age at marriage is less than 18 years. Marriage before the age of 18 years is prohibited in Bangladesh because the girls remain physically immature till the age of below 18 years. Media like TV also has a strong positive relationship with awareness. Because TV watching have more direct impact on the respondents. The regression coefficients for the ever-married women who watch TV is 1.410 and the corresponding OR is $4.094(\mathrm{CI}=3.676-4.559)$, which implies that the level of awareness about HIV/AIDS among the ever-married women who watch TV is 4.094 times higher than that of the ever-married women who don't watch TV. Electrification in the household reflects on the socio-economic index of a household, which relates the consciousness as well as AIDS awareness. The regression coefficients for the ever-married women who have electricity in the household is 0.510 and the corresponding OR is 1.665 $(\mathrm{CI}=1.486-1.866)$, which implies that the level of awareness about HIV/AIDS for the ever-married women who have electricity in the household is 1.665 times higher than that of the ever-married women who have no electricity in the household. The regression coefficients for the ever-married women who are not living with their husbands i.e. the women belonging to others (separated, deserted, divorced, widowed, and never married) is -0.340 and the corresponding OR is $0.712(\mathrm{CI}=0.598-0.847)$, which implies that the level of awareness about HIV/AIDS for the ever-married women who are not living with their husbands i.e. the women belonging to others (separated, deserted, divorced, widowed, and never married) is 0.712 times lower than that of the currently married women. The regression coefficients for the ever-married women living in urban areas is 0.702 and the corresponding $\mathrm{OR}$ is $2.017(\mathrm{CI}=1.789-2.274)$, which implies that the level of awareness about HIV/AIDS for the ever-married women living in urban areas is 2.017 times higher than that of the ever-married women living in rural areas. It occurs because in Bangladesh, urban areas are more developed than rural areas in terms of socio-economic factors.

\section{Conclusions}

From both bivariate and multivariate techniques, the study has identified the accountable factors of respondents and their husbands' education, exposure of electronic media like $\mathrm{TV}$, age at marriage, electrification, marital status and area of residence are significantly $(<0.01)$ associated with the level of awareness about HIV/AIDS. Therefore, it is the time to emphasize more on education, ensuring electronic media exposure especially to TV, institutional based sex education and necessary information to learn about HIV/AIDS for the young, adult and adolescents all over the country. For effective use of mass media, it requires careful planning, audience research, message development, pre-testing, dissemination strategy, evaluation, co-ordination with existing services, and linking mass media with interpersonal communication. As HIV/AIDS comes and kills us silently and any one can be infected any time by this tremendous enemy in absence of proper awareness, every cautious and alert person needs to participate as an active soldier in the battle of HIV/AIDS prevention through massive awareness building in Bangladesh.

\section{ACKNOWLEDGEMENTS}

The authors are very grateful to Professor Dr. Md. Nurul Islam, Head, Health Research Unit, Department of Statistics, University of Rajshahi, Bangladesh; to give me an opportunity to present a seminar, and to the honourable teachers and fellows of this department for their valuable comments and suggestions. Thanks also go to the editor and referees for their priceless comments and criticism, which led to greatly improved version of this paper.

\section{REFERENCES}

[1] Mamtaz, A. (1999): HIV / AIDS: Response to the Pandemic in Bangladesh. Journal of Preventive and Social Medicine (JOPSOM); 18(1):74-83.

[2] UNAIDS (2010): World AIDS Day Report, Joint United Nations Program on HIV/AIDS; Switzerland.

http://www.unaids.org/en/media/unaids/contentassets/docum ents/unaidspublication/2011/JC2216_WorldAIDSday_report _2011_en.pdf

[3] United Nations (2007): Asia: AIDS epidemic update. Regional Summary. UNAIDS/WHO, Geneva.

[4] World Health and Population (2007): Prosperity, Equity, Good Governance and Good Health: Focus on HIV/AIDS Pandemic and Its Feminization.

[5] Epidemiology and Basic Facts about RTI/STI and HIV/AIDS (2002): Curriculum on RTI/STI, Urban Family Health Partnership, 5.

[6] Chan, P. A. and Khan, O. A. (2007): Risk factors for HIV infection in males who have sex with males in Bangladesh. BMC Public Health 7(153) 1-8.

[7] ICDDR, B (2005): Health and Science Bulletin: Center for Health and Population Research; 3(1).

[8] Minichiello V., Paxton S., Cowling V., et al. (1996): University Students' Knowledge of STDs: Level, symptoms and transmission. Int J STD AIDS 7, 353-358.

[9] MOHFW (2011): National AIDS/STD Program, Directorate General of Health Services, Ministry of Health and Family Welfare (MOHFW), Dhaka, Bangladesh.

[10] UNAIDS and World Bank (2003): HIV/AIDS at a glance.

[11] Mondal, M. N. I., Takaku, H., Ohkusa, et al. (2009): HIV/AIDS acquisition and transmission in Bangladesh: Turning to the concentrated epidemic. Jpn J Infect Dis 62, 111-119. 
[12] Khan, M. A., Rahman, M., Khanam, P. A., et al. (1997): Awareness of Sexually Transmitted Diseases among Women and Service Providers in Rural Bangladesh. International Journal of STD and AIDS 8, 688-696.

[13] Rahman, M. M., Kabir, M. \& Shahidullah, M. (2009): Adolescent knowledge and awareness about AIDS/HIV and factors affecting them in Bangladesh. J Ayub Med Coll Abbottabad 21(3), 3-6.

[14] Sultana, N. (2009): Awareness on HIV/AIDS among the blood donors of a city hospital. Ibrahim Med Coll J 3(2), 63-66.
[15] NIPORT (2007): Bangladesh Demographic and Health Survey (BDHS), National Institute of Population Research and Training (NIPORT), Dhaka, Bangladesh.

[16] Shahidullah, M. and Bangali A. M. (1990): Assessing awareness and perception of AIDS. JOPSOM 4(9), 47-52.

[17] Rahman, M. S. and Rahman, M. L. (2007): Media and education play a tremendous role in mounting AIDS awareness among married couples in Bangladesh. AIDS Research and Therapy 4, 10-17. 